"The EUrASEANs: journal on global socio-economic dynamics"

Volume 3 (22); May-June, Year 2020;

ISSN 2539 - 5645 (Print)

Copyright (C) 2020, [The EUrASEANs]

on-line access: https://www.euraseans.com/3(22)

All issues of this journal are alternatively stored and archived by: the National Library of Thailand, Russian E-library and Index Copernicus

library of journals, Poland

\title{
STRATEGIC ANALYSIS FOR BUSINESS SUCCESS: THE CASE OF VGI COMPANY
}

\author{
IrinaV. Onyusheva \\ Turan University, Almaty, Kazakhstan \\ Minawat Machula \\ Treeraporn Manuthammathorn
}

Stamford International University, Bangkok, Thailand

The VGI Public Company Limited (VGI) is functioning under the umbrella of the BTS Group Holding Company, Thailand. The aim of this research is to consider, analyze and develop an integrated strategy for business success of VGI by means of exploring its internal and external business environment with the use of different business analytical tools. The paper outlines the current market conditions that VGI is operating under, followed by SWOT and PESTEL analyses and the 5 forces model by M. Porter. Marketing aspects are covered through STP, 7P's market mix, pricing and advertising policy.

Keywords: strategy; business success; Thailand, VGI

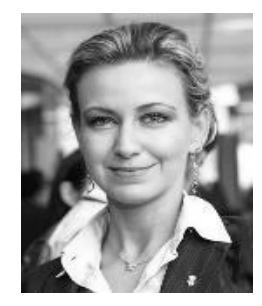

\section{Irina V. Onyusheva}

$\mathrm{PhD}$ in Economics, Full Professor of Turan University, Almaty, Kazakhstan.

Research interests: strategic management; economic competitiveness on both micro- and macrolevels; human capital development; HE management; knowledge economy; knowledge management; project management; management in education.

E-mail: dr.irina.onyusheva@gmail.com

\section{Minawat Machula}

Stamford International University, Bangkok, Thailand; International MBA Program. Research interests: international business management, strategic management, marketing.

E-mail: mmachula@gmail.com

\section{Treeraporn Manuthammathorn}

Stamford International University, Bangkok, Thailand; International MBA Program. Research interests: international business management, strategic management

E-mail: treeraporn.m@gmail.com 


\section{STRATEGIC ANALYSIS FOR BUSINESS SUCCESS}

\section{Introduction}

This study considers the VGI Public Company Limited, the businesses of which are widely presented at Thailand's market. The research uses data from the VGI's annual report as well as news and previous research studies on the same and similar topics. Our aim is to analyze the factual reasons why VGI is so well standing and maintains success in the advertising industry while there are so many competitors in this industry.

In 2019, Mr. Nelson Leung, CEO at VGI Global Media PLC declared that his company is a unique market leader and number 1 among out-of-home (OHM) media and offline-toonline (O2O) solutions ads platform in Thailand. In 2019, VGI revenues from ads service amounted approximately 4,049.8 mln baht, and its market share indeed made it number one company at its market (Marketing Oops, 2019). VGI also scored the highest in terms of market capitalization at 75,338.26 mln baht in the media and publishing sector (Epahamalao, 2019).

\section{Literature Review}

\section{Definition of the Related Variables}

Media: It refers to communication channels used to disseminate news, music, movies, educational content, promotional messages and other types of data. This definition covers various ways through which society communicates, including newspapers, magazines, television, radio, billboards, telephone, Internet and so on (MBN, 2020).

Advertising: A marketing tactics involving paying for space to promote products or services. The actual promotional messages are called advertisement, or ads in short. It is the act of calling public attention to an idea, product or service through notices paid for by a sponsor or a business. The goal of advertising is to attract new customers by defining the target market, to reach out to people and entice them to buy (Ward, 2018).

Out of Home Media (OHM): Anything outside home. In other words, it is not TV, radio, printed or online media. OHM include billboards and signs, ads on street furniture like bus shelters, ads in transit areas of airports and train stations, place-based media at buildings or stadiums. It focuses on reaching consumers during the day when people go to work or travel for other purposes (Heo, 2017).

VGI Public Company Limited: Established in 1998,this company is a unique market leader with exclusive access to behavioral data from their advertising, payment and logistics platform. VGI has been committed to become Thailand's most customer-oriented media company. They provide fully integrated offline-to-online (O2O) solutions by turning data into meaningful consumer insights and better experience from the 360-degree advertisement solutions. The company is constantly working on developing deeper understanding of the customer journey and helps brands navigate their customer journey at every stage of the purchasing process.

Offline-to-Online (O2O) Solutions: advertising through the integration of OHM and Online Media so that to match with target audience lifestyle by means of analyzing their behavioral data. This is a unique online field which enables the integration of online and offline media into one single advertising platform. In simple terms, it works as follows: people can click ads after seeing the same on out-of-home media. 
Offline media advertising (Out-of-Home). It is covering heavily mass transit networks in Bangkok as well as major residential and commercial outlets throughout the country. This type of advertising can be placed in many areas such as:

Transit Media: Inside public transport or in public transportation areas. The main purpose of transit advertising is to reach out to people and familiarize themselves with a certain brand (Vogt, 2020). In the case of Bangkok specifically, it is widely represented at BTS stations, in trains and on junctions, and also MRT stations and public buses.

Building Media: Ads placed inside and outside commercial and residential buildings.

Outdoor Media: Standard billboards in the first place and also digital billboards, both reaching mass audience. Here also belongs the so-called street furniture with LED projection, light boxes on the streets and so on.

Aviation: Advertising in the airports, on jet bridges, digital screens at the airports etc.

\section{Related Research Theories}

PESTEL Analysis: This is an analytical tool that effectively analyzes macroenvironment. It covers six key external factors as follows: political, economic, social factors, technological, environmental and legal factors. When analyzing the background of any enterprise, these six factors are often used for a closer look on the situation faced by the enterprise (Gillespie, 2007). It is often used in collaboration with other analytical business tools such as SWOT analysis and Porter's Five Forces to give a clear understanding of a situation and the related internal and external factors. This analysis tool also assesses macroeconomic changes that have impact on the development of the organization. This method allows companies become better in responding to the external changes that may deter the overall efficiency (Pérez, 2018).

Five Forces by M. Porter: This analysis model was proposed by Michael Porter in the early 1980s and later had a significant impact on the formulation of corporate strategies. The five kinds of abilities refer to the bargaining power of suppliers, the bargaining power of buyers, the entry ability of potential competitors, the substitution ability and the existing competitiveness of industry competitors. Different combinations of these five forces ultimately affect the interests of the industry and changes in them.

SWOT Analysis: This is a well-known model in business analytics of Strengths, Weaknesses, Opportunities and Threats of a company. SW part of this analysis covers the internal factors that the company can actually control, and the OT part of the analysis concerns external factors that the company cannot control. The purpose of SWOT analysis is to identify strengths as well as limitations that need to be overcome. In other words, SWOT shows you where to attack and where to defend your business. Also, SWOT results need to be applied appropriately in devising a smart and effective action plan.

Marketing Mix 7P's: This method was invented and published by E. Jerome McCarthy in 1960 in "Basic Marketing - A Managerial Approach for providing intangible services". The 7Ps help companies review and identify the essential factors affecting their product marketing process. The mix includes: Product or Service, Price, Place, Promotion, Process, People, Physical evidence (Hanlon, 2019).

STP: One of the business strategies applied by many businesses to find target customers and locate products at the market to help bring profits to businesses (Cousins, 2018). 


\section{STRATEGIC ANALYSIS FOR BUSINESS SUCCESS}

Segmentation: market segmentation (usually divided as per customer behavior, and also psychological, demographic or geographic) will help businesses allocate resources more effectively and focus on increasing profits and getting a competitive advantage over other businesses.

Targeting: To identify the target market, businesses must assess the attractiveness of each market segment. Then they choose one or more markets to enter.

Positioning: In order to position, a company must first find a difference; stand out in their product/service from competitors, thereby positioning it in the minds of consumers.

\section{Research Problem, Goals, Objective}

\section{Research Problem}

Here we would like to discuss two main problems. Firstly, in Thai media industry the current competition is really high as there are many competitors at this market. Secondly, traditional media and some offline media has been seriously declining while OHM and online/digital media have been on the rise among advertisers. Since digital disruption happened, every form of media has been trying to monitor and adapt to this newer trend and to other consequences of technological change. We often see that media entities are taking a proactive approach towards change, finding opportunities to set themselves apart, responding to the needs of their targeted audiences. In such a way, they are usually able to persist and make a successful breakthrough in the industry (Fig. 1).

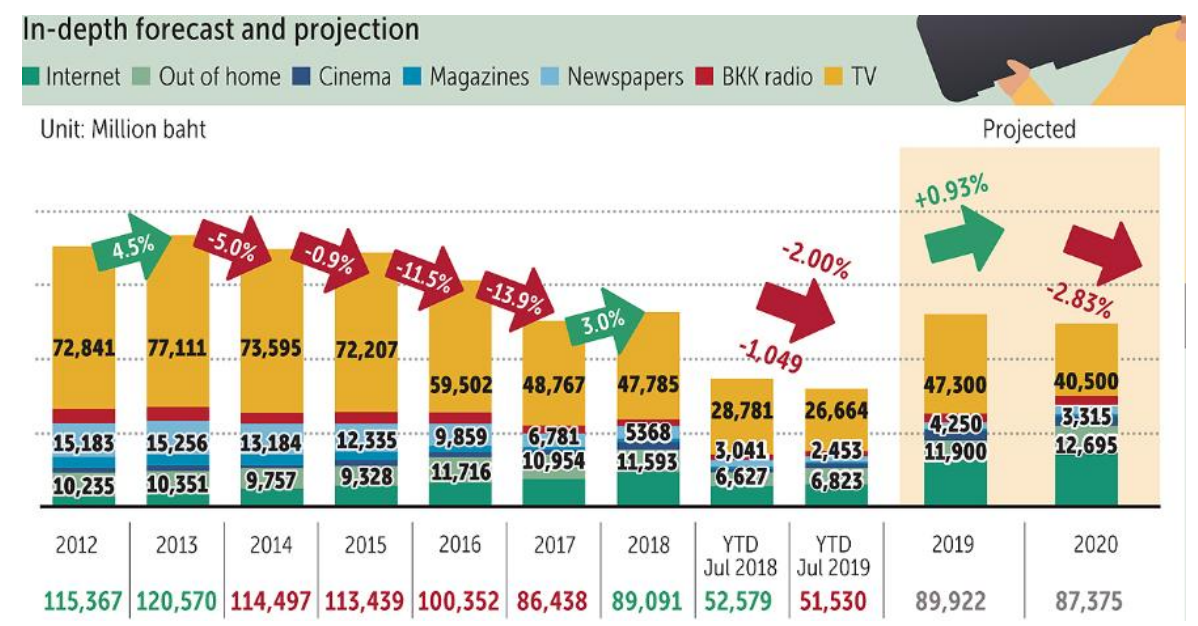

Figure 1 - In-depth forecast and projection (Sources: Media Intelligence, 2019; UTCC, 2019)

Businesses are well aware of the importance of advertising. They are readily paying more for the new types of ads with the purpose of making consumers aware or reminded of their products/services. Today, they do not only advertise on traditional media such as newspapers, television or mass media to convey their message about own products and services to consumers but also use images and alternative support methods.

In Thailand, one of the most widely used and popular advertising types is the so-called in-transit advertising, which is getting increasingly popular and diverse. The question arises as to why do businesses like using this advertising in their marketing campaigns? Our team 
will analyze this form of advertising on the example of VGI Public Company Limited, although it does not cover all types of transit advertising.

\section{Research Goals}

Our central research goal here is to study the sharing advertising business model, its key success factors and its strategy at the high competition market.

\section{Research Objective are formulated as follows:}

- To evaluate the current market trends within the media industry of Thailand;

- $\quad$ To understand the competitive advantages of VGI;

- $\quad$ To evaluate the marketing mix 7P's associated with VGI;

- To identify what is most effective for VGI's sustainable growth strategy.

\section{Key Research Findings}

\section{PESTEL Analysis}

Political: Political factors play a significant role in determining the impact of profitability and opportunity as external factors. Our analysis will be focusing on political stability and government support since a large share of VGI's investment and strategy involves the country's infrastructure.

Under the leadership of Prime Minister Prayuth Chan-o-cha, the positive impacts from the government support have been as follows:

- This government has performed massive transit extensions, including those of BTS Sky train and MRT routes. It has a huge positive impact on VGI because now the company has more space for its media ads.

- Government support has indirectly increased the passenger volumes on public transportation. For the company, this means more opportunities for the people to see the ads.

- Free trade areas: The volume FDI and the number of investors coming to Thailand has seriously increased in the several recent years. This could potentially generate greater inflow of investment for VGI as well.

The negative impact from law and regulation has been as follows:

- In Thailand businesses cannot post ads about alcohol-containing products. Thus, VGI needs to be extra careful about this category of products (Siamrath, 2017).

Economic: VGI is successfully using the country's economic indicators such as growth rate, inflation and also economic indicators of the selected industries. Data on Thailand's consumer spending is of vital importance for company's forecasts regarding growth.

As Thailand is one the leading players within the ASEAN community, the nation has managed to maintain a low and stable inflation rate and well capitalized domestic financial system. Although the inflation rate increased from 0.87 in 2019 to approximately $1.05 \%$ in 2020, it has been driven mostly by food prices and transportation costs. In 2020, EIC foresees that Thai economy will be picking up gradually, following its slightly improving export growth in comparison to 2019. In addition, strong baht is the key factor for both buyers and service providers. 


\section{STRATEGIC ANALYSIS FOR BUSINESS SUCCESS}

TMP Outdoor (2019) wrote that Thailand has one of the most creative advertising industries in the world. The country's traditional media are still very much active as well. Growth of the advertising industry in 2019 was around 4.8\%, reaching 124 bln baht (US $\$ 3.65 \mathrm{bln}$ ). Thai advertisement has the most rapid growth in such categories as outdoor, transit, and in-store advertising.

Their estimated spending in 2019 was around 15 bln baht. Thailand OHM industry holds the 3rd as per spending. High urbanization rate and the growing volume of traffic in Bangkok keeps outdoor advertising in Thailand strong.

This is also a highly fragmented market with only a few international players. 2 of the 3 largest media owners in Thailand belong to this segment. This has led to higher media prices and better quality of digital OHM ads. These media owners are also aggressively expanding into other ASEAN countries like Indonesia. Thailand OHM ad sales are expected to increase by 7-9\% this year already. Overall economic situation is very supportive for the OHM sector overall and VGI company in particular. Economic situation in the country is the key factor that impacts growth of the advertisement businesses. At the same time, expansion onto new, emerging businesses requires considerable funds and other resources of the company.

Social: Society's culture and the way of doing things in general impact both organizations and the environment around them. Shared beliefs and attitudes of population play a great role in how marketers at VGI will understand the customers of a given market and how they design the marketing message for consumers. Social factors to be included into such an analysis are as follows:

- Demographics and skills' level among the population;

- Class structure, hierarchy and power structure in the society;

- Education level as well as education standards;

- Culture (gender roles, social conventions etc.);

- Leisure interests / Lifestyle preferences.

The current population of Thailand is approximately 66.41 million. The average age in Thailand is 38.1 years and the life expectancy is 71.9 years for females and 78.5 years for males (Bank of Thailand, 2020). The INRIX Global Traffic Scorecard reported other important details on the population of Thailand:

- Bangkok is always in the top-10 by traffic jams in the world;

- People in this capital city, working people especially, are spending approximately 4 hours per day in transport;

- Most people in the country spend $70 \%$ of their time outside their homes.

All of the above is not that in terms of social standards of living, for people themselves. However, such a metropolis lifestyle is a very good impact for VGI. People have more opportunity to see the ads on the streets, roads, on billboards and so on. Transport infrastructure in Thailand is strongly supporting VGI business development in terms of sales volumes.

Technological: Technologies are disrupting various industries these days. Transportation industry is a good case to illustrate this point. Over the last 5 years, this industry has been transforming really fast, not even giving chance to the established players to cope with the changes. Technology is considered to be an integral part of Thai economy. According to the Bank of Thailand, most of Thai businesses are using advanced technologies 
to support their business operations. Such advanced technologies include: Internet banking, online media ads, mobile phone and other IT-related achievements (Bank of Thailand, 2019). Thus, consumers nowadays are more inclined towards technologies as such. These forces companies focus on digital strategies by developing greater product and service offerings via digital platforms.

This is one of the reasons why VGI has entered the $\mathrm{O} 2 \mathrm{O}$ market segment. It allows VGI benefit from greater innovations and technological advancement in general. Continuously upgrading the company's digital advertising media to be up-to-date to keep image, increase visibility and attract its target audiences requires considerable expenditures. Thus, if the company cannot create enough demand to generate revenue to cover the investments, it may suffer losses and this will surely have adverse effect on the whole business, its financial standing and operational results.

Environmental: Generally speaking, Thailand's environment is quite supportive for VGI's business development. Before entering new markets or starting a new business at the existing markets the firm should carefully evaluate the environmental standards applied at these newer markets. Some of the environmental factors should be considered long beforehand.

Thailand is located in the Southeast Asia, the country has the area of 513,000 square kilometers and is bordering with Myanmar, Laos and Cambodia. Thailand has been placing significant efforts into the development of public infrastructure and transportation networks. The government has approved the infrastructure development plan for 2015-2022 back in July 2014 with the budget of THB 2.4 trln.

The key goal of this plan is total restructuring of Thailand's transportation (Bank of Thailand, 2014). The government has the intention to improve public transportation network and thus reduce the nation's reliance on road transportation. This is also supposed to be decreasing traffic congestions on Bangkok roads.

Thailand is also the key manufacturing hub with great accessibilities for the neighboring countries (Bank of Thailand, 2014).

Legal: The legal system of Thailand contains a combination of traditional Thai and Western laws and the key participants of the justice system are nominated by the Senate and are then appointed by the King of Thailand. Jurisdiction of various civil and criminal cases is managed in three different tiers, including the Court of First Instance, the Court of Appeal and the Supreme Court of Justice. In Thailand there are some limitations on the use of media ads, thus, VGI needs to monitor ads information at all times.

The main regulation related to VGI is commercial contract law and public law, allowing private sector for concession agreement. Changes in laws directly related to VGI's business operations include the following: new laws or amendment to laws concerning business operations of VGI Group may have adverse effects on its business, financial position and operating results of the company if the latter is unable to promptly adjust its business operations to be in compliance with the applicable laws. The company is closely monitoring the laws concerning business operations of VGI Group and has a work plan to ensure that all business operations of VGI are in compliance with the currently applicable laws. 


\section{STRATEGIC ANALYSIS FOR BUSINESS SUCCESS}

\section{Porter 5 Force Model}

\section{Bargaining power of suppliers (Moderate)}

VGI has already identified specific, their own suppliers, they have reached agreements on price, timing and provision of all materials for the production process.

Suppliers may affect the profitability and product competitiveness of enterprises in any industry mainly by raising input factor prices (this refers to the cost of production factors and also remuneration) and also by reducing the quality of materials.

Suppliers are usually the companies that have rather stable market positions and are not subject to market competition as such.

Their products are purchased in an endless stream, so each buyer cannot become the supplier's one and the only customer, essentially important for survival.

Moreover, if a product offered by a supplier is differentiated and has characteristics that cannot be duplicated, it is difficult for the buyer to convert to other products or find substitutes for them.

Suppliers are also comfortable with implementing intra-industry alliances or integration measures that buyers are unable to use to counter suppliers' bullying.

VGI is a listed giant in Thai media industry, and most people think its suppliers have reliable bargaining power.

The key suppliers of VGI's business operations consist of 2 types:

- VGI's strategic shareholders (represent $66.5 \%$ of the total advertising income): BTS, Kerry Logistic, MACO

- General market partners (represent $33.5 \%$ of the total advertising income): Airlines, Office buildings, Line cooperations

Based on the above proportion of income mostly generated from strategic shareholders, it could be anticipated that the bargaining power of suppliers is not strong and is currently under the company's control, without significant impact from suppliers' side.

\section{Bargaining power of buyers (High)}

Usually, buyers improve their bargaining power mainly by lowering the prices on the side of suppliers' products and services, or by requiring suppliers to provide products with better quality, thus affecting the profitability. Generally, the bargaining power of buyers mainly depends on two aspects:

First, the total number of buyers is not large, but the purchase amount of each buyer is enormous, accounting for a large proportion in the total sales volume of suppliers. Most people in Thailand watch VGI's advertisements in places like subway stations, which is a good example of such a case.

Second, what a purchaser needs a standardized product or service. Under the market economy, it is entirely feasible for the purchaser to buy standardized products or services from multiple suppliers. Therefore, as more and more social media companies are entering the market, consumers have more and more choices.

Thus, VGI also faces stronger bargaining power of buyers. The company should pay enough attention to this trend, since, in a long term, it may become risky.

The overall media spending in Thailand produces high competition in this industry and thus higher bargaining power for buyers. 


\section{Threats from new entrants (Low)}

There is no doubt that Thailand's social media industry has become a convenient stage for Internet giants, mostly overseas ones. Countless new entrants are gearing up to try, each wanting a piece of the pie. These "recruits" bring in not only money, technology and ideas, but also a considerable threat to the industry's established players. Entering this industry requires substantial capital and resource investments, especially in part of infrastructure and processes' establishment.

All of the above is making new entries a hard thing to implement, thus, we consider them to be a low risk for VGI.

\section{Threat of new substitutes (Low)}

As the locations for placement of ads are limited, many of them are subject to exclusive rights for particular companies. For example, if you want to place an ad on the BTS Sky Train, you need to contact VGI, and only this particular company.

Two enterprises in the same industry may produce competition because their products are substitutes for each other. Such competition derived from substitutes will affect the competitive strategies of all enterprises in the same industry. Due to prosperity of Thai media in the several recent years and continuous strengthening of cultural and entertainment consumption, abundance of products and services provided by enterprises inside and outside this industry has gradually started threatening the status of the pioneering enterprises in this industry.

Level of competition among the existing competitors (Low)

VGI is the number one among all OHM companies in Thailand. Some of them choose to make competitors become their business partners.

The interests of enterprises working in the same industry are often closely related. When formulating their competitive strategies looking at other enterprises, businesses usually aim to gain relatively stable competitive advantages. Therefore, when each enterprise implements its competitive strategy, conflicts and confrontations at the market are inevitable, and such situations leads to competition among enterprises. Such competition is usually reflected in price, marketing methods, products/services offers and so on.

\section{SWOT Analysis}

Strengths:

VGI is a unique market leader and number 1 among OHM media and $\mathrm{O} 2 \mathrm{O}$ ads platforms in Thailand. VGI can integrate online and offline Media into one single advertising platform.

The company offers various types of out-of-home advertising media, done by VGI and their partners. The offered types of media ads cover in the whole metropolis area.

VGI currently has 70\%+ market share of the out-of-home media ads market.

High credibility: VGI is the biggest OHM company in Thailand and is also in top-5 in Asia. The company can boast perfect financial statements.

This increases the confidence on the side of customers, investors and partners.

VGI gathers and analyzes data from a wide range of sources. This helps with getting measurable results and also with reaching out to the right category of target audience. 


\section{STRATEGIC ANALYSIS FOR BUSINESS SUCCESS}

The company offers good locations for ads' placement.

\section{Weaknesses:}

High production costs of raw materials, printing ads, transportation, installation and so on.

High investment costs of new technologies. Given the scale of expansion and different geographies the company is planning to expand into, VGI needs to allocate more money into technology improvement and upgrade of its whole system.

The price of VGI ads is not affordable for small and medium businesses. It is more suitable for big companies with enormous budgets.

There are some limitations regarding space, time and location of ads. Customer will see these ads only when they leave home and go to specific areas.

Outside advertisement is always dealing with mass impressions. Thus, it is always hard to determine the needed target audience and focus on it. Lack of segmentation is a serious limitation.

\section{Opportunities:}

VGI is the only business with the exclusive rights to manage advertising space on BTS Sky Train network (since 1999) and BRT( since 2010).

Inorganic growth: VGI had to purchase the shares from Big OHM media companies to expand their business and cover the market more fully. These included: PlanB, Maco, Aero, DemoPower, Anymind Group and ACP, all taking place in 2019.

After VGI made previous competitors now partners, the company got less competition in $\mathrm{OOH}$ media ads at Thai market and thus became ready to develop new, additional forms of advertising.

The demand to use public transportation like BTS is constantly increasing, and government support is actively provided for its further development (Post Today, 2019).

New trends in consumer behavior and at the tech market can open up new opportunities for the company. Such changes provide great opportunities in terms of new product categories' development. For example, in switching from more traditional OHM to O2O solutions.

In 2019 alone, the BTS Sky Train extended its route onto 18 new stations. This obviously increases the space for transit ads' placement.

\section{Threats:}

There are many forms for OHM replacement, such as advertising on taxi cars, buses, billboards etc. All of them have much lower fees as compared to the transit ads.

New technologies developed by competitors or by new market disruptors could become serious threats to VGI business in the medium and long term.

Global economy overall is going down these days. This can affect customer decisions in new advertisement purchasing.

This is the online media era. The Internet offers much faster and cheaper means of advertising products and services.

Since the number of views in this subsector of ads cannot be controlled as such, there are difficulties with ensuring the effectiveness of ads. 


\section{Marketing Mix 7 P's}

Product: VGI provides traditional offline out-of-home media platforms and is quickly moving in the direction to offer a complete ecosystem of offline-to-online solutions.

Advertising via transit media: Ads cover more than 30 BTS stations, 1,000 retailers on these stations and 20,000+ BTS screens, displays and signs.

Billboards and street furniture advertising (outdoor media) provide ads on more than 1,000 billboards and LED projectors, thus covering all prime areas. Street media coverage include 180 light boxes, 42 digital screens and more than 300 smaller panels (mostly under flyovers).

Advertising in office building and residential areas (office media) cover multiple offices, shopping malls and residential areas - in total, 495 buildings and 2,114 screens in Bangkok alone.

Advertising in the airport covers more than 360 LED screens, 343 digital screens, 57 jet bridges and 70 in-flight media.

Demonstration service (free product sampling) in trade areas and on BTS stations. Such ad campaigns are aimed to provide samples and passes to events for more than 1,000 nationwide stores. This is a relatively easy way to get interaction with more than $40 \mathrm{mln}$ audience.

Offline-to-online media (O2O) integrates online and offline media forms into a single advertising platform. People click on ads after seeing the same ad on a out-of-home media platform. Sometimes this also involves showing ads on Facebook on LINE.

Price: Transit and office media ads are managed by VGI itself. The price depends on the types of media, size of a media carrier and the exact location; the rate is calculated per month.

Place: All central districts of Bangkok and also the selected suburban areas.

Promotion: VGI offers special prices for their packages. The package may look as follows: Digital LED at a BTS station + Immerse + Connect (No Lock Box), all for the price of 2,450,000 per month (Jenpasit, 2019).

People: VGI is committed to guarantee safety and occupational health of all its employees, contractors and also that of the local community in the areas where it is operating. For ads which involve direct communication with customers (samples' distribution and events) VGI provides training for employees. Demonstration service on BTS stations assumes interaction with more than 100,000 customers per day, thus, safety and healthcare become of vital importance.

Process: Depending on types of media, it may be directly attributed to VGI's company or its subcompanies. Example: Transit and Office media are managed by VGI itself. Outdoor media is managed through a 33.2\%1 stake in Master Ad Public Company Limited (MACO). Aviation and Activation media are managed through a 30.0\% stake in Aero Media Group Company Limited (Aero Media) and 40.0\% shareholding in Demo Power (Thailand) Company Limited (Demo Power). All this is information from VGI's annual report, as of 2019.

Physical evidence: All ads placed on Bangkok transportation means, office areas, shopping malls, junctions and so on. Each of these areas has been carefully selected to make sure it is easy to see so that ads smoothly interact with people when they are out of homes. 


\section{STRATEGIC ANALYSIS FOR BUSINESS SUCCESS}

\section{Segmentation, Targeting and Positioning [STP]}

Segmentation: VGI is a B2B-oriented business, therefore, emotional factors related to consumers directly do not play an important role in the decision-making process. Since VGI's customers are companies, most of them want to see ROI and effectiveness from the solutions that VGI is offering.

Besides, enterprises themselves have a great demand for information. VGI always has sufficient and detailed information on all ads' parameters, their usage and potential advantages.

Targeting: VGI targets mostly businesses with significant financial capacity and mainly in big cities as Bangkok and Pattaya (but mainly Bangkok).

Positioning: VGI focuses on analyzing how much the service can help their customers save time, money and resources. Therefore, they always work with the motto "TARGETING TO THE RIGHT PEOPLE AT THE RIGHT TIME".

Market trends in the media industry of Thailand

High competition

Flat growth in the traditional sector and high growth in the digital sector

Correspondence and sensitive to economic growth and fluctuations in it

Competitive Advantages of VGI

Exclusive cooperation with BTS

Strong partnership with other leading players, including Line Play, Kerry Logistic, PlanB, MACO [Partnership here means that competitors are gradually changing into partners]

$\mathrm{O} 2 \mathrm{O}$ ecosystem. End users will see similar ads and promotions via OHM, online and then elsewhere. Customers can pay easily via Rabbit Line pay, for example, if they see repeated ads in messengers already.

Outstanding marketing mix of VGI

Products are unique and at the same time, they are covering the whole ecosystem, with all types of media, including $\mathrm{O} 2 \mathrm{O}$.

Places of advertising are all located at strategic areas, attractive for general audience and difficult to be replaced by other locations.

Since advertising processes are covering the whole ecosystem, product variety is quite effective.

Sustainable Growth Strategy

Business diversification through investment in payment systems and logistics.

Synergy with all types of media, both offline and online.

Expanding to neighboring countries, first of all Malaysia and Vietnam.

\section{Conclusions}

Being a market leader is critical for growth, a good marketing strategy and a solid implementation plan are still needed. Strategies, action and the choice of marketing tools depend on both internal and external factors. Our analysis has emphasized on STP (segmentation, targeting, positioning) as well as on the Service Marketing Mix (7P's) and SWOT following PESTEL analysis of VGI's performance. 
VGI can easily compete following their current strategy since value; growth and innovation are the core elements forming the foundation of this business. Together, they define the strategic directions and the structural plan as well as the driving force behind Company's vision which is "Pioneering Solutions for Tomorrow". Company's value believes in long-term value creation. Such a set of priorities would certainly help the company achieve industry-leading growth. Innovations implemented by the company show its commitment to digital technologies and $R \& D$ excellence while developing and launching a new generation of products and solutions that are meeting ever-changing consumer demands.

Many businesses today find $\mathrm{O} 2 \mathrm{O}$ solutions to be very much successful in their advertising. This includes: McDonald, AEON, COMICO etc. And this is yet another proof that VGI's OHM ads in Thailand will continue to remain successful.

The key strategies supporting significant growth of VGI include:

- Exclusive partnership with BTS

- Full integration of offline-to-online $(\mathrm{O} 2 \mathrm{O})$ solutions into one ecosystem

- Offering 360- degree view on all advertisement solutions

- Changing competitors to partners in joint work with many other media operators, including MACO, PLANB and Hallo Bangkok

- Investing in non-media industry to expand own ecosystem. For example, investing in Kerry Logistic, Lowson 108 and Sahagroup

Ultimately, this paper could be beneficial for further strategic research on the businesses similar to VGI since this study provides insightful understanding of the whole market.

\section{References:}

Bank of Thailand (2014). Industrial Focus. Retrieved from Bank of Thailand: https://www.boi.go.th/tir/issue/201409_24_9/42.htm

Bank of Thailand (2019). Use of Mobile Banking and Internet Banking. Retrieved from: https://www.bot.or.th/App/BTWS_STAT/statistics/ReportPage.aspx?reportID=688\&language= eng

Bank of Thailand (2020). Thailand in Brief. Retrieved from: https://www.boi.go.th/index.php?page=demographic

Cousin, J. (2018). STP Marketing, The Startup. Retrieved from: https://medium.com/swlh/stpmarketing-6deb6b010b5

Epahamalao, (2019). 10 Big share in MEDIA group "BEC - MAJOR". Retrieved from: https://www.epahamalao.com

Gillespie, A. (2007). PESTEL analysis of the macro-environment. Foundations of Economics, Oxford University Press.

Hanlon, A. (2019). How to use the 7Ps Marketing Mix. Retrieved from: https://www.smartinsights.com/marketing-planning/marketing-models/how-to-use-the-7psmarketing-mix/

Heo, S. (2017). What is Out of Home Media? Retrieved from: https://www.emcoutdoor.com/blog/2017/10/what-is-out-of-home-media-an-introduction/

Jenpasit, (2019). Example of Out of Home ads price rate. Retrieved from: https://www.thumbsup.in.th/price-of-out-of-home-ads

MBN (2020). What is media? Definition and meaning. Retrieved from: https://marketbusinessnews.com/financial-glossary/media-definition-meaning/ 


\section{STRATEGIC ANALYSIS FOR BUSINESS SUCCESS}

Pérez, E. (2018). Scanning the Environment: PESTEL Analysis. Retrieved from: https://www.business-to-you.com/scanning-the-environment-pestel-analysis/

Post Today (2019). Government supports public transportation. Retrieved from: https://www.posttoday.com/economy/news/578571

Siamrath (2017). Alcohol ads are to be guilty. Retrieved from: https://siamrath.co.th/n/20804

TMP Outdoor (2019). Thailand Out-of-Home Advertising: An Overview. Retrieved from: http://tpmoutdoor.com/blogpost/thailand-outdoor-advertising/

Vogt, C. (2020). What Is Transit Advertising, Chron. Retrieved from: https://smallbusiness.chron.com/transit-advertising-25935.html

Ward, S. (2018). Advertising and the way to go about it. Retrieved from: https://www.thebalancesmb.com/advertising-2947182

Paper submitted

Paper accepted for publishing

Paper published online
08 February 2020

24 April 2020

O2 June 2020 